\title{
Law Libraries as Publishers \\ Producing Articles Instead of Issues
}

Benjamin J. Keele, Indiana University Robert H. McKinney School of Law

$\mathrm{M}$

y first job was delivering newspapers. I managed to skim through each paper as I walked my route, starting my daily newspaper habit. I thought of each day's issue as my standard unit of news. Years later, I now rely more on newspaper sites that frequently add articles throughout the day. Now I think of each article as a discrete unit.

The same thing has happened to law reviews. I doubt many people read each journal issue cover to cover, but the issue was the standard unit of legal scholarship. Legal research databases and journal websites have atomized issues into articles. Based on how I read articles and my faculty request them, I would guess most readers give little thought to which issue contains a given article.

If I am right about this, then journal editors and the librarians that support and advise them may benefit from shifting how they think about what they are publishing. When I was a journal editor, I saw my job as producing two issues. Now, I would say the editor's job is to edit and publish a certain number of articles each year.

This seemingly mundane reframing can lead to major changes in a journal's workflow. The most significant is that articles can be published as they are finished instead of waiting for the entire package of articles assigned to an issue. As a journal editor, I

This seemingly

mundane reframing

can lead to major

changes in a

journal's workflow. based the entire editing process on issues. Everyone worked on one stage (say, checking citations), and once most of the articles were through that stage, everyone shifted their attention to the editing stage. Delays in the editing of one article often resulted in other articles being held, even though they had finished the stage they were in.
If I had not been committed to publishing a group of articles at once, I could have set up a completely different production process. As soon as each article was finished, it could proceed to the next stage. Journal members working on one article would not be held up by delays in another article. Authors motivated by quick publication would know that prompt responses to editor's questions would directly contribute to their piece being published.

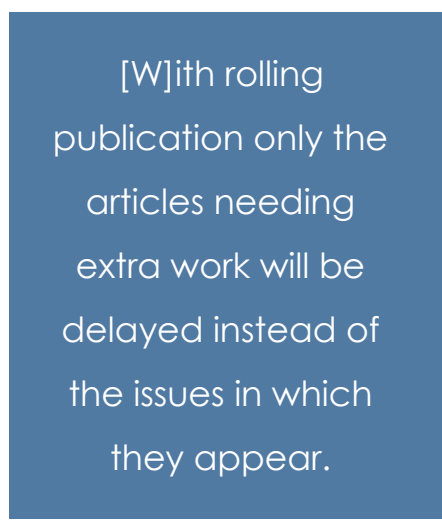

One of the three journals I advise plans to implement this rolling publication this year. I anticipate it will result in swifter publication of articles. Every year brings some challenging articles, but with rolling publication only the articles needing extra work will be delayed instead of the issues in which they appear.

Rolling publication is not mutually exclusive with print issues or other multi-article formats. Each article should be posted to the journal site and sent to the databases as it is finished. When the editors decide an issue is complete, then the articles can be assembled and printed as an issue. Legal Information Review has adopted this approach, adding issues throughout the year in HeinOnline and then printing a single issue with all articles published that year.

The primary case in which rolling publication may not work is a symposium or themed issue. In that case, many articles may refer to each other and may be best read together.

If you have any thoughts on law libraries publishing, please contact me at bkeele@indiana.edu. 